Arthur Smith Woodward and his involvement in the study of Human Evolution

\title{
Christopher Dean*
}

Cell and Developmental Biology,

University College London,

Gower Street,

London, WC1E 6BT.

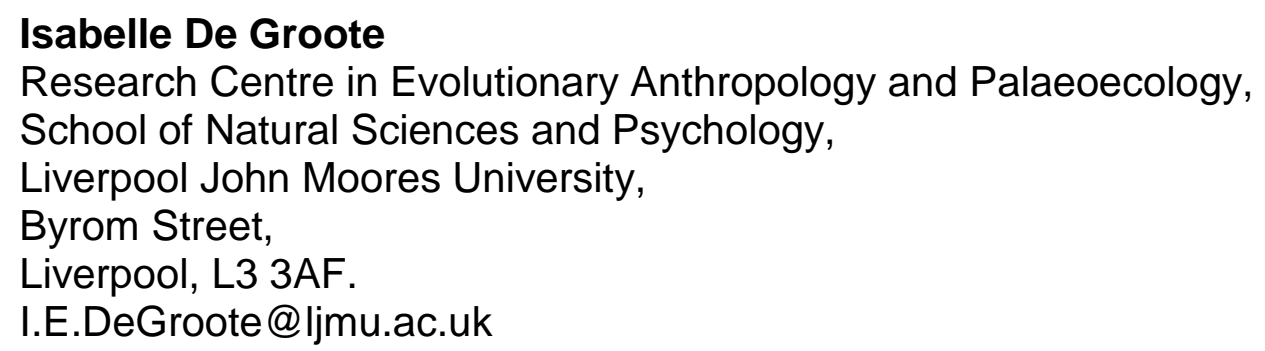

Chris Stringer

Human Origins Research Group,

Earth Sciences Department,

Natural History Museum,

Cromwell Road,

London, SW7 5BD.

c.stringer@nhm.ac.uk

* Corresponding Author (e-mail: chris.dean@ucl.ac.uk)

7964 words (including abstract of 173 words)

6 Figures

Abbreviated title; Arthur Smith Woodward and Human Evolution

Keywords: Piltdown Man. Arthur Smith Woodward. Charles Dawson

Abstract 
In 1884, Arthur Smith Woodward first met Charles Dawson, a solicitor and industrious amateur collector, antiquarian, geologist, archaeologist and palaeontologist. This began a long association and friendship centred on their mutual interest in palaeontology and human evolution. Dawson devised a complicated plot focused around the ancient river gravel deposits at Barkham Manor near the village of Piltdown, Sussex. In these gravels he planted stone tools and fossil mammal remains together with the lower jaw of an ape and numerous modern human cranial bones to deceive the scientific establishment into believing an early human ancestor had been found in his own back yard. Cleverly devised to provide anatomists and archaeologists with evidence for concepts that they wanted to believe were true, Dawson fuelled numerous contentious debates among scientists that quickly attracted international attention. Nothing could be more unfortunate than such a respectable scientist as Arthur Smith Woodward was taken in by the events of 1912, and then subsequently swept along by them well into his retirement right up to the time of his death in 1944.

(NB no heading for first paragraph) Long before Arthur Smith Woodward became interested in and involved with human evolution he had achieved fame as a vertebrate palaeontologist and geologist both within the UK and abroad. Appointed to the British Museum (Natural History) - hereafter BMNH - as an assistant in 1882 he had risen to become Keeper of Geology by 1901 and was elected FRS in June the same year, aged 37. It was not, however, until 1912 when Smith Woodward was approached by Charles Dawson, a solicitor and amateur collector of fossils and antiquities, that he became involved with the discoveries at Piltdown in Sussex and with human evolution.

From this time onwards the events surrounding the discoveries at Piltdown snowballed into an obsession with human evolution that preoccupied Smith Woodward well into his retirement and right up to his death in September 1944. After her husband's death, Lady Maud Smith Woodward approached Sir Arthur Keith and invited him to write a Foreword for "The Earliest Englishman" a popular book that Smith Woodward was working on when he died. "The Earliest Englishman (1948)," reveals the breadth of context that Smith Woodward brought to the field of human evolution. It explores for the general reader the geology, archaeology, comparative fauna and environmental reconstructions of the Piltdown site, as well as the anatomy of the bones themselves. Lady Maud Smith Woodward was the daughter of the famous geologist Professor Harry Seeley and clearly in her own right very knowledgeable about the discoveries and events surrounding Piltdown Man (Shindler, 2013). She had been intimately involved with many of the discoveries and was often present at debates concerning Piltdown. Having lost his sight towards the end of his life, Arthur Smith Woodward had relied completely on his wife to pen this, his last book and publication. It is, therefore, highly likely "The Earliest Englishman" contains many insights that both he and his wife shared into how the events developed. This book and other published letters and notes written by people closely involved in the Piltdown affair, or by people who knew them 
personally, provide us with the best account of this period in Smith Woodward's life.

In this review of Arthur Smith Woodward's contribution to human evolution, it seems most appropriate to dwell primarily on the events surrounding the discovery, description and subsequent defence of the Piltdown remains and in so doing review the geology, archaeology and faunal remains from Piltdown that occupied his life so fully from 1912 onwards. Besides Smith Woodward's involvement with Piltdown, he also contributed primary descriptions of other fossil hominin remains. In November 1927, he wrote a summary account of the cranium from Broken Hill (now Kabwe), Zambia, for Nature and in June 1938, well into his retirement, he described a newly discovered cranium from Singa, Sudan. At the end of this review, Smith Woodward's thoughts on the Broken Hill and Singa fossils, the events surrounding their discovery and the circumstances that led to him to describe these fossil hominins, can be appreciated with greater perspective. A number of invaluable publications provided an unparalleled resource without which this short account would not have been possible: we acknowledge them here: Russell, 2003; Spencer, 1990a,b; Walsh, 1996; Weiner, 1955; 2003; Woodward, 1948.

\section{Charles Dawson and the discovery of the Piltdown remains}

Smith Woodward wrote (Smith Woodward, 1948, page 5, "The Earliest Englishman"): "When I first met [Charles Dawson] in 1884 ... he was collecting fossil-bones of extinct reptiles from the quarries in the Wealden sandstone and his collection was soon important enough to be accepted by the British Museum." "He always took care, indeed, to submit his discoveries to experts, who discussed them and stimulated him to further exertions. He was a solicitor by profession, but during his leisure he lived in the world of scholars who were engaged in research." "Charles Dawson was one of those restless people, of inquiring mind, who take a curious interest in everything round them - from an unusual form of ancient rushlight-holder to the latest device in electric torches; from an old parchment deed to a horn-like growth on a horses head; from the proverbial live toad in a stone to an escape of inflammable gas from the ground; from fossils and minerals in the Wealden rocks to the tools and leavings of prehistoric man. Nothing came amiss to his alert observation."

Dawson and Smith Woodward had not met in 1912 since a trip together to Cliff End, near Hastings, in January. Then a letter arrived dated 15th February 1912 from Dawson to Woodward: "I have come across a very old Pleistocene (?) bed overlying the Hastings bed between Uckfield and Crowborough which I think is going to be interesting. It has lots of stained flints in it so I suppose it is the oldest known flint gravel in the Weald. I [found a] portion of a human (?) skull which will rival H. Heidelbergensis in solidity, Charles Dawson", (Spencer, 1990b, p 17).

Apparently, Woodward replied to this letter but trips abroad delayed him seeing the finds for himself. Nonetheless, it seems curious Dawson did not offer to bring the 
fossils to show Smith Woodward or at least mention them again in his next letter dated 12th May 1912: "I expect to be in London tomorrow (Monday) at the Law Courts and hope to have a chance of getting to see you during the day or the next day." "Since I saw you I have been writing on the subject of "The 13th dorsal vertebra" in certain human skeletons, which I believe is a new subject." "I send you the results and if you think well enough of it I should be very much obliged if you would introduce the paper for me at the Royal Society. I am anxious to get it placed at once because I have had to work on the photographs under the nose of Keith and his assistant." "I gather from the latter person Keith is rather puzzled as to what to make of it all, and I want to secure priority to which [I] am entitled...... I have had no further opportunity of doing more work in our gravel bed, but I am tracing the same deposit to various other points in the Weald, which may help our determination of the geological horizon, someday. Charles Dawson", (Spencer 1990b, p 22).

Clearly, Dawson felt able to share his feelings about the anatomist Arthur Keith with Smith Woodward, which suggests the two men knew each other well enough to share confidences of this kind. The assumption must be, however, that Smith Woodward did not feel able to communicate Dawson's story about the extra thoracic vertebra present in some modern humans to The Royal Society, although no reply to Dawson explaining this exists. It can be construed that Dawson's response would have been to reignite Smith Woodward's interest in the finds from Piltdown that were in any case likely to trigger greater general scientific interest. In a letter written a mere 11 days later (dated 23rd May 1912) Dawson again wrote to Smith Woodward, this time wanting to show him flint implements and fossils (probably molar fragments of Stegodon and Hippopotamus). "Sometime - tomorrow (Friday), probably after lunch I will bring the pieces of skull and a few odds and ends found with it, in the gravel-bed. ......." (Spencer, 1990b, p 22).

Smith Woodward continues the story as follows (Smith Woodward 1948, page 8, "The Earliest Englishman"): "It was now the Spring of 1912, and Mr Dawson brought his discoveries to me to talk about them and to learn whether his conclusions were justifiable. We had often worked together in extricating fossils from the Wealden rocks near Hastings, indeed we had collected for the British Museum the best known specimen of the ganoid fish, Lepidotus mantelli, and a fine pelvis of the dinosaur Iguanodon. We decided to work together again in the gravel pit on Barkham Manor farm at Piltdown to try and find the remaining pieces of the new human skull."

\section{The sequence of the discoveries in 1912}

During one of his many collecting trips in the Hastings area, Charles Dawson had met a young French priest who was also an amateur collector of fossils. Teilhard de Chardin had been sent by his Order to further pursue his studies at Ore Place near Hastings. Previously, he had taught chemistry and physics at a Jesuit College in Cairo for 3 years. By April 1912, Dawson had already shown one or other of the cranial vault bones belonging to the Piltdown cranium to others, including Teilhard 
de Chardin (Figure 1; I-L). Letters from Teilhard de Chardin to his friend, Pelletier, in Jersey and also to his parents (Spencer, 1990, page 20) describe how Dawson showed him the chocolate brown vault bones, hippo and elephant fragments and flint tools on 20th April 1912. Others also reported being shown a skull bone by Dawson (wrapped in newspaper) reportedly from the Barkham gravels.

Teilhard de Chardin wrote in his diary on 2nd June 1912 that he, Charles Dawson and Smith Woodward, went to dig at Piltdown together and that Smith Woodward found a piece of occipital bone in the spoil heaps of debris and that Teilhard de Chardin himself had found a piece of elephant tooth. Teilhard de Chardin was not present at any further digs that summer and returned to France in mid-July 1912.

Two years earlier, in January 1910, Dawson had asked Smith Woodward if Mr Barlow, the conservator at the BMNH would send him some preserving solution to 'prevent [lguanodon] fossils scaling and cracking on drying out'. This solution arrived and was acknowledged in January 1911 by Dawson: "I think Mr Barlow's solution will act very well", (Spencer, 1990b pp 7 and 11). It must not then have seemed out of the ordinary to Smith Woodward that Dawson had treated the first finds from Piltdown is a similar way to the Iguanodon fossils. Smith Woodward writes (Smith Woodward 1948, page 59, "The Earliest Englishman"): "The colour of the pieces which were first discovered [at Piltdown] was altered a little by $\mathrm{Mr}$ Dawson when he dipped them into a solution of bi-chromate of potash in the mistaken idea that this would harden them."

On the fourth Saturday in June 1912 in the evening Dawson himself later wrote that he "struck part of the lowest stratum of the gravel with my pick and out flew a portion of the lower jaw from the iron-bound gravel" (Walsh, 1996, p 19). This event was witnessed by both Lady Smith Woodward and by Arthur Smith Woodward himself. Then in August 1912 over a long three-day weekend, three pieces of the right parietal bone were recovered, one on each day, again in the spoil heaps. Smith Woodward later wrote that each fitted together perfectly. Several flint implements turned up over the various digs, each member of the team finding one of them (Figure 1; B, D).

First announcement of 'Eoanthropus dawsoni' at The Geological Society, 18th December 1912

A group of experts including Grafton Elliot Smith, then Professor of Anatomy at The University of Manchester, William Pycraft, osteologist and ornithologist at the $\mathrm{BMNH}$, Arthur Swayne Underwood professor of dental surgery at Kings College London and Mr Frank Barlow, conservator, preparator and technician at the BMNH had been working hard since the summer to fit the vault bones and jaw bone together and interpret the reconstruction.

At the Geological Society meeting in December 1912 (Dawson and Woodward, 1913), where the Piltdown remains were first described, Smith Woodward presented the reconstructed skull (Figure 2; a). His key points were that the 
cranium was altogether normal with no trace of disease or exaggerated growth but that enough traces of midline landmarks were preserved to allow a reconstruction of the brain case. This reconstructed vault was rounded with a high forehead and very thick bone; the cranial capacity measured $\sim 1070 \mathrm{cc}$. These, and a number of other features, (including an asymmetrical cerebellum, deep glenoid fossa of the temporal bone, an oval external auditory meatus with a downwards and forwards sloping long axis) all confirmed the 'human character' of the skull vault. The jawbone however, was exactly the reverse and appeared almost wholly ape-like. It possessed no mylohyoid ridge, but most regrettably was missing the mandibular condyle that would have articulated with the glenoid fossa of the cranium. Nonetheless, the two molar teeth were, according to Smith Woodward, key to associating the mandible and the brain case. The marked and uniform flatness of the molar wear pattern had apparently never been observed among apes. This unique combination of characters warranted the announcement of a new genus and species, Eoanthropus dawsoni.

But the pivotal question that remained unanswered was whether the canine tooth and chin would have been human-like or ape-like. Unfortunately, both were missing. Arthur Keith, Professor of Anatomy and Conservator of the Hunterian Museum at The Royal College of Surgeons remarked that, in his opinion, the chin and anterior teeth had been reconstructed as too ape-like and that the skull was not enough like a modern human. Nevertheless, he emphasised how significant the fossil find was. Keith was clearly pushing for an ancient Pliocene date for Piltdown and a morphology that more closely matched that of the Galley Hill fossils discovered in 1888 but described by him as essentially modern human-like, yet considered to be very ancient (Keith, 1910; 1911). Smith Woodward had ended his presentation by describing the associated remains of Mastodon sp. (Figure $1 \mathrm{C}$ ) Stegodon sp. Hippopotamus sp., Equus sp (Figure $1 \mathrm{E}$ ), Castor fiber (beaver) and Cervus elaphus (red deer) at the site, all comingled with the hominin remains, so there was plenty of scope for speculation about the geological age.

Charles Dawson had opened the packed meeting at the Geological Society with a description of how he had first discovered the site at Piltdown. He then went on to describe the geology of the site and the 'flint-implements'. Smith Woodward was a strong supporter of "eoliths" (Figure $1 \mathrm{E}$ ), flints supposedly showing evidence of having been worked or used, and of them being early evidence of humans far back before the Pleistocene. Their presence at Piltdown, along with other examples of more advanced looking "palaeoliths" (Figure $1 \mathrm{D}$ ), as well as the strangely mixed faunal assemblage, all fuelled debate about an Early Pleistocene or even earlier pre-glacial Pliocene date for the Piltdown gravels.

Opinion was split about the geological age of the specimen and only four out of nine discussants were comfortable that the jaw and cranium were from a single individual. David Waterston, professor of anatomy at Kings College London, felt the "brain case was human in practically all its essential characters" while the jaw "resembled in all its details the mandible of a chimpanzee". Waterston suggested 
the glenoid fossa would be different if the jaw belonged to it and that it clearly belonged with a human-like mandibular condyle as Smith Woodward had admitted. Waterston later became quite outspoken on this matter; "Having an entirely chimplike jaw except for a human-like condyle was like having a chimp-like foot on an essentially human thigh and leg" (Waterston,1913).

Grafton Elliot Smith finished the proceedings with what was by all accounts a rather rushed 'off the cuff' account of the morphology of the Piltdown brain cast. He pointed out its very primitive and ape-like features with a deeply excavated temporal area "to form a bay between the inferior temporal pole and the cerebellum" but, he thought, with "exciting indications of the brains later expansion here in modern man", perhaps alluding to some evidence of speech and language capacity. All this suited Elliot Smith's 'brain first hypothesis' very well. In his view, the growth of the brain "preceded the refinement of the features of the somatic characters in general", for example as evidenced by the large brain of Piltdown Man combined with its ape-like jaw.

\section{Disagreements about anatomy}

The intense public interest and press coverage both at home and abroad must have been overwhelming. Immediately following the official announcement at the Geological Society on 18th December 1912, differences of opinion began to surface about how exactly the remains should be reconstructed. Arthur Smith Woodward, supported at least in part, by Grafton Elliot Smith, stood his ground against the most voluble of these critics: Arthur Keith at The Royal College of Surgeons. Smith Woodward, Elliot Smith and Keith were the most senior anatomical figures involved in the discussion. Each was expert in different aspects of human, primate and/or comparative anatomy. Almost immediately conflicts arose between them as they each saw unique potential to promote and defend their own anatomical skills and clinch their own unresolved theories on human evolution. In Smith Woodward's case, there was also the need to adopt a professional resolve to defend his own corner.

Keith was convinced that the jaw reconstruction was too ape-like but that the cranium was a "blunder" and ought to show a much more modern and bigger brain. This would be in line with Keith's own theory; that modern humans had their origins far back in "the vast antiquity of time". Keith's alternative cranial reconstruction also had profound implications for what Elliot Smith had already declared about the anatomy of the brain of Piltdown Man.

Many of these differing views were expressed openly at the International Congress of Medicine on 11th August 1913 in London. That day, a group of experts first heard Smith Woodward put his view about the Piltdown reconstruction to them at the BMNH in the morning. In the afternoon, they heard Arthur Keith's point of view at the Royal College of Surgeons. While some justifiable improvements to the reconstruction of the vault bones may have eventually and quietly resulted from this meeting, Keith's new reconstruction of the mandible, chin and canine tooth 
was far too reminiscent of both the Mauer mandible and the Galley Hill skull, and quite improbable (Figure 2; B).

With hindsight, we can look back and see how individual ambitions and rivalries were acted out with claims and counter-claims about the science of cranial reconstruction, brain size, brain evolution, the thickness of the vault bones, the pattern of blood vessels on the inner aspect of the vault bones, the incompatibility of the jaw and cranium and especially about predictions regarding the morphology of the missing chin and front teeth of the Piltdown mandible.

\section{The sequence of the discoveries in 1913}

On the 3rd of July 1913 Charles Dawson wrote to Arthur Smith Woodward telling him he had found a portion of frontal bone from a human skull at Barcombe Mills and that while it was not a thick skull, it might, in his opinion, have been a descendent of Eoanthropus. Once again, Dawson asked for Barlow's "recipe for gelatinising, as the bones look in a bad way" (Spencer, 1990b, p 70-71). This announcement by Dawson of fossil finds from Barcombe Mills was two years ahead of a subsequent announcement about the discovery of the 'Piltdown 2' remains from nearby Sheffield Park, which supposedly only happened in 1915.

As excavations at the Piltdown 1 site began again in August 1913 (Figure 3), shortly after the International Congress of Medicine meeting in London, Teilhard de Chardin rejoined the team following a brief trip to Jersey. Being busy with religious commitments he was only able to join the Piltdown dig at weekends. First, some small bones from the nose were recovered and then two weeks later on 30th August 1913, Teilhard de Chardin spotted the all-important missing ape-like canine tooth (Figure $1 ; \mathrm{F}$ ) in one of the spoil-heaps surrounding the site. Hailed as a triumph for Charles Dawson and Arthur Smith Woodward, the ape-like canine represented a serious worry for Arthur Keith who (just three weeks after his bold presentation at the International Congress of Medicine) retreated into a puzzled acceptance that Piltdown Man was indeed a stranger amalgam of human and apelike traits than he had previously ever thought possible.

\section{Rising concerns 1914 - 1917}

As already indicated, right from the start, a number of other anatomists had objected to the idea that all the hominin remains from Piltdown belonged to a single individual. David Waterston, at King's College London, had been forthright in his view that the ape jaw did not belong with the human cranium (Waterstone, 1913). Now, two dental surgeons, W. Courtney Lyne and Arthur Swayne Underwood made some uncomfortable observations, first from radiographs of the third molar socket, which suggested to them this tooth had not quite erupted (unlikely, as it turns out, since a contact facet for it exists on the distal aspect of the second permanent molar). Second, from the strange wear pattern on the canine tooth, which indicated it was perhaps from a juvenile, an upper - not a lower tooth, or even a deciduous ape tooth (Lyne, 1916; discussion section). All this forced further soul-searching about whether the Piltdown remains represented just one individual, 
two, or as Lyne rather rashly suggested, even three. Moreover, Elliot Smith's overenthusiastic interpretation of the brain endocast had become increasingly irritating to many fellow neuroanatomists. Johnson Symington, then professor of anatomy at Queen's University Belfast wrote; "Most anatomists in this country believe there has been too much rash speculation regarding the significance of the Piltdown fragments. Conclusions on the 'primitive' brain of Piltdown are highly speculative and fallacious" (Symington, 1916; Spencer, 1990b p 141).

A long-planned meeting at the Royal Society finally took place on $19^{\text {th }}$ February 1914 at which Elliot Smith gave his own account of the Piltdown brain endocast and of the cranial reconstruction. Of that meeting, Solly Zuckerman (Zuckerman, 1973), distinguished professor of anatomy at the University of Birmingham, eventually wrote that, "Arthur Keith having failed to persuade his anatomical and zoological colleagues the Piltdown skull was wrongly reconstructed, carried the dispute into the open, finally attacking Elliot Smith at the Royal Society meeting". It is clear that Arthur Smith Woodward was himself doubtful about some of the details of the reconstruction and of their interpretation. In "The earliest Englishman" (1948 page 64) he wrote; "Symington had urged caution about over interpreting endocasts of brains because of the blurring effect of the meninges. I sometimes wonder whether the late Sir Grafton Elliot Smith felt these difficulties when he had presented his detailed account of the brain of Piltdown Man to the Royal Society in 1914, because he never completed the paper for publication".

Meanwhile, during a trip to London in 1913, William King Gregory, distinguished vertebrate palaeontologist at the American Museum of Natural History, must even then have heard rumours that Piltdown might be a hoax. In September 1913, at Smith Woodward's own home in London, Gregory and Teilhard de Chardin were present at a gathering with other palaeontologists. Teilhard de Chardin stayed several nights at the Woodward's (Walsh, 1996, p 43) before leaving on a short trip to Jersey where he wrote to his parents, "he had me write my name on a piece of cloth covered with signatures of geological celebrities" (the 'piece of cloth' of course being a table-cloth - currently on display in the Department of Earth Sciences at the Natural History Museum). It seems unlikely there would not have been lively discussion about everything to do with Piltdown, even perhaps about rumours of a potential fraud. Later in 1914, William King Gregory wrote about the Piltdown fossils that, "it has been suspected by some that they are not old at all; that they may even represent a deliberate hoax, a Negro or Australian skull and an ape jaw artificially fossilised and 'planted' in the gravel-bed to fool scientists" (Gregory, 1914). Who, we might ask, was the source of this rumour? Harry Morris, a local bank clerk and amateur archaeologist, already had a flint from Piltdown which he claimed was faked, and by this time may have been openly talking about it. But William King Gregory quickly qualified his extraordinarily accurate observation by writing that none of the experts who had scrutinised the specimens, the site and its surroundings doubted the genuineness of the discovery (Gregory, 1914). 
In June 1914 a large bone tool (Figure 1; A), resembling a long flat digging-stick (or cricket bat to some) was found about a foot underground but "sticky with yellow clay", indicating it had actually come from the lowest flint-bearing layer of the excavation pit (Walsh, 1996, p 49). The implement had been hit by the workman Hargreave's pickaxe under the hedge at the Piltdown site. This find was probably intended to be something of a show-stopper, but the question is by whom? Either the forger was trying to divert attention away from the bones and teeth and back to the supposed transitional lithics record at Piltdown with this new discovery suggesting bone tools may actually have existed prior to both the flint eoliths and palaeoliths (McNabb, 2006). Or alternatively, someone might have planted the 'cricket bat' to warn the forger they had been found out (Stringer, 2012). Then World War 1 broke out in August 1914. Later, in 1915, when things had settled a bit, Smith Woodward in his Museum guide to Piltdown had by then quietly raised his estimate of the cranial capacity to $1300 \mathrm{cc}$ (Figure 2; C), much closer to Keith's estimate (Walsh, 1996, p 51).

Mounting criticism from home and abroad about the unlikely nature of Piltdown Man as a single individual was now growing. Besides William King Gregory, Ales Hrdlička. Gerrit Miller, W. Courtney Lyne, Franz Weidenreich, Harald Sicher and later Alvan Marston, as well as others, all doubted the jaw and cranium belonged to a single individual. But none openly claimed, or perhaps even imagined, the remains to be fraudulent as William King Gregory had reported - perhaps rhetorically - in 1914. Among the most concerned may well have been Teilhard de Chardin. Despite having been present in 1912 when Smith Woodward found some occipital fragments Teilhard de Chardin had not actually seen the mandible until shortly before his visit to the Woodward's home in August 1913 on his way to Jersey. While in London, he looked at fossils in the BMNH and saw the exhibition of remains from Piltdown at the morning session of the Congress of Medical Anatomists. He also noted "an enjoyable evening spent with a certain Gregory (from New York Museum, an important contact) and an ornithologist from the British Museum, [William Pycraft]," (Spencer 1990b, p 80). It was only 3 weeks after this that Teilhard de Chardin found the canine tooth on 30th August 1913. Later on, and clearly concerned about something to do with Piltdown, he appears to have expressed his reservations in letters to his family while a stretcher-bearer during the 1914-18 World War (Thackeray, 2011). Eventually he published a paper in 1920 in which he expressed his doubts that the mandible belonged to the cranium (Teilhard de Chardin, 1920). For Teilhard de Chardin it would have been very difficult to doubt the judgement of his friends Charles Dawson and Arthur Smith Woodward in a publication, although he was not one to shy away from independent thinking. For example, he wrote to his parents on $15^{\text {th }}$ August 1913 that Smith Woodward was much criticised by Keith "who wants (and rightly so I believe) to have the skull reassembled in a new way" (Spencer, 1990b, page 80).

On 15th January 1915, Charles Dawson wrote to Smith Woodward (Russell, 2003, $\mathrm{p} 239$ ) that he had found a frontal fragment at Sheffield Park resembling the bones from Piltdown 1. On 30th July 1915, Dawson wrote again to Smith Woodward 
saying he now had a new molar tooth from Sheffield Park. "It's a 1st or 2nd right molar" - "The roots broken". Smith Woodward, it would seem, never mentioned these letters to anyone but may perhaps have actually seen the specimens when he visited Dawson personally as he is known to have done when he was ill and dying (Walsh, 1996, p 54). However, by this stage, Smith Woodward is said by his wife, Maud, to have regarded Piltdown 2 (Figure 4; A, B, C) as something Dawson had imagined; existing in his imagination, implying he never did see the remains while Dawson was alive. After Dawson's death in August 1916, Smith Woodward asked Dawson's widow to send them to the BMNH. To add to this puzzle, it was clearly the case that Dawson had discussed and had probably shown (Walsh, 1996, p 54), these finds to others, including Edwin Ray Lankester in the Summer of 1915, who then mentioned the Piltdown 2 finds in his book Diversions of a Naturalist (Lankester, 1915 - see also Russell, 2003, p 242).

On 28th February 1917, six months after Charles Dawson's death, Arthur Smith Woodward finally announced that fragments of a frontal, occipital bone and of a molar tooth, closely resembling the original finds from Piltdown, had actually been recovered by Dawson in 1915 from a second site. According to Smith Woodward, Dawson had at one time explained to him that these fragments came to light among heaps of stones raked off a ploughed field at Sheffield Park - but would not or could not tell him the exact place. Amongst these same heaps 'a friend' had apparently later found a fragment of fossil rhinoceros tooth. Henry Fairfield Osborn wrote "[They are] exactly those [fragments] which we should have selected to confirm the comparison with the original type" (Walsh, 1996, p 61). An explanation for Smith Woodward's earlier caution about Piltdown 2 might have been the lack of clarity about the exact location of the Piltdown 2 site, something that would in the end sow seeds of doubt in the mind of Joseph Weiner.

\section{Arthur Smith Woodward and the post-Piltdown years}

Arthur Smith Woodward (1864-1944) retired in 1924 aged almost 60, after 42 years at the BMNH. It has been said that he never stepped foot in the BMNH thereafter. Nevertheless, his interest in human evolution continued and he even moved to Haywards Heath, closer to Piltdown, in order that he might still continue excavations there.

Three years before Smith Woodward's retirement, Mr Ross Macartney, the managing director of a company with a mine at Broken Hill, or Kabwe, in what today is Zambia, brought the fossilised remains of a hominin cranium to London (Figure 5 right) and to the BMNH as a generous gift (Woodward, 1921). One of the mine workers, Tom Zwigelaar had extracted a near-complete cranium as well as a tibia from a deep fissure, while other remains were collected from miners and from around the site, including a fragment of the upper jaw of another cranium, and various postcranial bones representing several individuals (Hrdlička, 1930). Arthur Smith Woodward was quick to describe the cranium as looking "strangely similar to the skull of the Neanderthal or Mousterian race found in the caves of Belgium, France and Gibraltar" (Woodward, 1921). But Woodward concluded; "the shape of 
the brain-case and the position of the foramen magnum are so different that we may hesitate to refer the two skulls to the same race". "Even the Heidelberg jaw is slightly narrower and shorter than [the matching jaw] must have been". Many of Woodward's anatomical observations are acute and he attributed the find to a new species, 'Homo rhodesiensis'. In his conclusion he drew on Elliot Smith's theory that the "refinement of the face was probably the last step in the evolution of the human frame", thus in still retaining the Neanderthal-like face, Homo rhodesiensis might, Smith Woodward proposed, with its more modern brain-case "revive the idea that Neanderthal man is truly an ancestor of Homo sapiens".

The subsequent monographic description of the Kabwe cranium fell to William Pycraft at the BMNH since Smith Woodward had by this time retired. Unfortunately, Pycraft's perspective and judgement about human anatomy and human evolution fell some way short of Smith Woodward's. He had previously demonstrated this in his rather brusk responses to Gerrit Miller of the Smithsonian who in 1915 had published a lengthy comparative analysis of the Piltdown jaw based on many chimpanzee, gorilla and orang-utan mandibles. Miller concluded that any attempt to combine the jaw and cranium of Piltdown would produce a primate that differed fundamentally from all others (Walsh, 1996 p 51). In his opinion no "blending or intermediate morphology" existed at all in any region. Moreover, Miller suggested the Piltdown canine was an upper tooth and not a lower. Pycraft had replied on behalf of the BMNH and accused Miller of setting out to "confirm a preconceived theory, a course of action which has unfortunately warped his judgement and sense of proportion" (Spencer, 1990a, p 103).

This episode was clearly not forgotten. Following publication of Pycraft's description of the Kabwe cranium, Ales Hrdlička of the U.S. National Museum (now The Smithsonian Institution National Museum of Natural History) wrote pointedly; "Mr Pycraft has done a very conscientious piece of work. If as appears from the reviews of his work, his conclusions are not meeting with favour, it is mainly because he has chosen to associate organically with the Rhodesian skull remains of which no man can say with full confidence that they belong to it; because he has seen more in the morphology of these additional remains than others can see; and because he makes of the Rhodesian man a new genus ("Cyphanthropus"). These are grievous sins, which may or may not be outweighed by the painstaking work on the skull" (Hrdlička, 1930). The beautifully preserved Broken Hill cranium is now often regarded as a member of the Middle Pleistocene species Homo heidelbergensis (Buck \& Stringer, in press).

The cranium from Singa, Sudan, (Singa 1), was discovered in February 1924 by the Governor of the Fung Province of Sudan, Mr. W. R. G. Bond (Figure 5 left). It was recovered from the seasonally exposed base of the banks of the Blue Nile approximately 200 miles South (upstream) of Khartoum. It is now known to be more than 130,000 years old, and represents an early form of Homo sapiens (Buck \& Stringer in press). The Government Geological Adviser in the Anglo-Egyptian Sudan, G. W. Grabham, made the cranium available for study and described the 
geological context of the find (Grabham, 1938). But how Arthur Smith Woodward came to describe the cranium and how William Pycraft came to prepare many of the drawings for this publication is interesting.

In all likelihood, Smith Woodward worked on this cranium at the Royal College of Surgeons and William Pycraft also must have gone there to prepare the figures, some of which are 'by permission' of the Royal College of Surgeons and are of crania in collections there. The short period of time between the publication of the description of Singa 1 in June 1938 and the registration of this fossil (M 15546) at the BMNH around November 1938 suggests this (pers. comm. Robert Kruszynski). At this time Arthur Keith was working on a description of the Florisbad skull, discovered in 1932 by T. F. Dreyer, having been sent a cast from Johannesburg by the anatomist Professor Raymond Dart (Keith, 1938). Besides this, Keith was describing the Swanscombe fossils (found between 1935 and 1936 by Alvan Marston) and was making comparisons with yet another new reconstruction of the Piltdown cranium (Keith, 1939). It may have been Keith who suggested to Smith Woodward that he describe the Singa cranium. This kind of mutual support for large-brained hominins being ancient in origin would have suited both men very well.

Smith Woodward noted the remarkable narrowness of the frontal region of the Singa cranium (but which is brachycephalic) and concluded that in many respects, but not all (for example in the prominent supraorbital ridges) it generally resembled that of modern Homo sapiens Bushman crania (Woodward, 1938).

If the descriptions of the Singa cranium and of the Swanscombe fossils cemented a late-life bond between Arthur Keith and Arthur Smith Woodward, that had in the past been anything but congenial, then the events that followed in 1938 bear testimony to this. Arthur Keith wrote in the Foreword to "The Earliest Englishman" (page xi); "Of the various honours that have fallen to my lot none has touched me more deeply than that which Smith Woodward paid to me in the summer of 1938. He had resolved to erect a monument at Piltdown to mark the site of discovery and to keep green the memory of his friend Charles Dawson. He invited me to unveil the monument and I gladly accepted the invitation." (Keith, A. page xii Foreword to "The Earliest Englishman" Smith Woodward (1948). "At these earlier disputatious meetings of the Geological Society I fear I played the part of the stormy petrel. Were the earlier participants of the Piltdown strife to return now (1948) nothing would surprise them more to find that as time went on Smith Woodward and I, instead of drifting farther apart over Piltdown issues drew nearer and nearer to each other in our interpretation of the Piltdown riddle" (Keith, A. 1948, page xi Foreword to "The Earliest Englishman").

Arthur Smith Woodward died in 1944, thankfully never knowing the truth about the 'fossil' in which he believed until the very end of his life (Figure 6).

\section{The forger}


Charles Dawson (1864-1916) was elected Fellow of Geological Society (1885) and Fellow of The Society of Antiquaries (1895) but his greatest ambition, to be elected Fellow of the Royal Society, eluded him. We now know Charles Dawson was also a serial forger, always over-eager to be recognised for his 'big discoveries' and 'breakthroughs' (Russell, 2003). It may be that his great ambition to be recognised by figures of authority was what spawned the Piltdown fraud.

In the early 1950s, professors Joseph Weiner, Kenneth Oakley and Wilfrid Le Gros Clark devised, in collaboration, a series of objective tests designed to get to the bottom of the Piltdown saga once and for all. It was the lack of information about the locality of Piltdown 2 that originally put Joseph Weiner onto the scent of the fraud. He even wondered if the Piltdown 2 finds had originally been at the Piltdown 1 site and then carted away with soil to mend roads further afield. That thought had also occurred to Edwin Ray Lankester at the announcement of the Piltdown 2 finds in 1917. Lankester pointed out that "it was a possibility - although highly improbable - that the piece of the frontal bone and also the molar tooth now described belonged to the same individual as that represented by the imperfect skull and lower jaw already known. But this could not be true of the fragment of the occipital bone..." (Woodward (1917; discussion section). In this way, Weiner went on to think about human error, or interference, mixing up the real picture. That, in turn, led him to consider human fraud in grinding down the teeth to look worn, since there was no obvious natural explanation for the occlusal surfaces of the worn molars not being co-planar or well-aligned. Removing the mandibular condyle and breaking the jaw to remove the anterior dentition and mid-line symphysis seemed like clear attempts to thwart a diagnosis of the jaw being human-like or ape-like.

Later on Weiner wrote that with regard to the anatomical knowledge that Dawson might have possessed, "I must emphasise that for someone like Dawson, with 15 20 years of interest in archaeology and evolution, a man of undoubtedly high intelligence, frequently in contact with palaeontologists, who knew the Hunterian Collection at the Royal College of Surgeons well, and who had in his possession a cast of the Heidelberg jaw amongst other things, it would be by no means difficult to acquire the necessary [anatomical] knowledge" (Weiner, 1973).

Weiner, Oakley and Le Gros Clark (see Weiner, 1955; 2003) identified three staining techniques that had been employed: potassium bichromate, iron ammonium sulphate and Vandyke brown. Specimens stained using an iron salt (ferrous ammonium sulphate - or 'iron alum') were then oxidised by dipping them in chromic acid, potassium dichromate or 'bichromate of potash' to precipitate iron oxide on the surface. (A consequence of this is that the sulphate ion in 'iron alum' also replaces the phosphate ion in hydroxyapatite lattice, which then weighs less).

All important fluorine tests then showed $0.1 \%$ in the cranial bones - but less $0.03 \%$ in teeth and jaw (and so thus of a younger age). Nitrogen tests showed $3.9 \%, 5.3 \%$ and $4.3 \%$ respectively in the teeth and jaw i.e. equivalent to fresh bone 
(4.1\%) but only between $1.4 \%$ and $0.1 \%$ in the cranial vault bones suggesting values equivalent to older anorganic bone (Weiner, 2003).

Several of the 'palaeoliths' at Piltdown were actually stained Neolithic flints, and the faunal material was derived from many other sites, with most of it similarly stained. 'Eoliths', it is now clear, are not tools at all and occur naturally at Piltdown and elsewhere, which may explain why Dawson initially appeared indifferent to their discovery at Piltdown. Later, he became more outspoken about them, taking sides with others such as Louis Rutot and Marcellin Boule who had never regarded them as man-made artifacts. In effect, the eoliths at Piltdown may have deflected from the supposed archaeological evidence of a transitional lithic culture that Dawson was trying to fabricate and draw attention to with the 'palaeoliths' and 'cricket bat' (McNabb, 2006).

In Chapter six of The Earliest Englishman (page 55), Smith Woodward recounts that Mr. John Cooke, an artist, had been employed to reconstruct a life-like impression of the Piltdown skull, which was eventually also used as the frontispiece of The Earliest Englishman (Figure 2; F). Woodward recounts that "Mr Dawson, indeed, on seeing this portrait, smiled and observed that he thought he could match it in Sussex today". When Weiner and Oakley went to tell Arthur Keith what they had discovered he was astonished, but after some while eventually exclaimed "yes I almost felt they kept on finding things with which to confute me personally" (Weiner, 2003).

\section{Acknowledgements}

We thank Mike Smith and the organisers of the Symposium on Arthur Smith Woodward for inviting us to write this review. We would like to extend our special thanks to Robert Kruszynski for his help and support and also for providing material for the talk given by CD at the Symposium on Arthur Smith Woodward held at $\mathrm{BM}(\mathrm{NH})$ on 21st May 2014. We thank our colleagues, currently involved with us in a wider project on Piltdown, for their input through many discussions over the past few years: Silvia Bello, Laura Buck, Linus Girdland Flink, Adrian Lister, Simon Parfitt and Karolyn Shindler. We are also grateful for the comments and observations of two referees.

\section{References}

Buck, L. T. \& Stringer, C, B. (in press) A rich locality in South Kensington: The fossil hominin collections of the Natural History Museum London. In; The Pleistocene on the hoof! Aspects of Quaternary palaeontology in honour of Andy Currant. Special Issue of the Geological Journal

Chardin, P. Teilhard de 1920. Le cas de l'homme de Piltdown. Rev des questions scientifiques (Bruxelles) 77, 149-155. 
Dawson, C. \& Woodward A. S. 1913. On the discovery of a Palaeolithic human skull and mandible in flint-bearing gravel overlying the Wealden (Hastings Beds) at Piltdown, Fletching, (Sussex). Quarterly Journal of the Geological Society London. 69, March 1913 - Read December $18^{\text {th }} 1912$.

Grabham, G. W. 1938. Note on the geology of the Singa district of the Blue Nile. Antiquity. A quarterly review of archaeology, 12, 193-195.

Gregory, W. K. 1914. The dawn man of Piltdown, England. The American Museum Journal, 14, 189-200.

Hrdlička, A, 1930. The skeletal remains of early man. Washington: Smithsonian Institution Miscellaneous Collections volume 83, page 119.

Keith, A. 1910. A new theory of the descent of man. Nature 85, 206.

Keith, A. 1911. Ancient types of Man. Harper, London and New York.

Keith, A. 1938. The Florisbad skull. Nature 141, 1010-1010.

Keith, A. 1939. A resurvey of the anatomical features of the Piltdown skull, with some observations on the recently discovered Swanscombe skull. Journal of Anatomy 73, 155,234.

Lankester, E. 1915. Diversions of a Naturalist. Methuen. London.

Lyne, W. C. 1916. The significance of the radiographs of the Piltdown teeth. Proc Roy Soc Med (London) Odontological Section, 9, 33-66. See Discussion section pages 52-62 by; Arthur Smith Woodward, Arthur Keith, Arthur Underwood, Grafton Elliot Smith, William Pycraft, Montau F. Hofson, J. G. Turner \& Courtney Lyne (reply).

McNabb, J. 2006. The lying stones of Sussex: An investigation into the role of the flint tools in the development of the Piltdown forgery. Archaeol. J. 163, 1-41.

Russell, M. 2003. Piltdown Man. The secret life of Charles Dawson \& the world's greatest archaeological hoax. Tempus Publishing Ltd, Gloucestershire UK.

Shindler, K. 2013. Piltdown's victim Arthur Smith Woodward. Evolve, issue 11, pages 32-37.

Spencer, F. 1990a. Piltdown a scientific forgery. Based on research done by lan Langham (1942-1984). Natural History Museum Publication, Oxford University Press, London, Oxford \& New York 
Spencer, F. 1990b. The Piltdown papers 1908-1955. The correspondence and other documents relating to the Piltdown forgery. Natural History Museum

Publication, Oxford University Press, London, Oxford \& New York.

Stringer, C. B. 2012. The 100-year mystery of Piltdown Man. Nature 492, 177-179.

Symington, J. 1916. Endocranial casts and brain form; a criticism of some recent speculations. Journal of Anatomy and Physiology (London) 50, 111-130.

Thackeray, J. F. 2011. On Piltdown: The possible roles of Teilhard de Chardin, Martin Hinton and Charles Dawson. Transactions of the Royal Society of South Africa 66, 9-13.

Walsh, J. E. 1996, The scientific fraud of the century and its solution: Unravelling Piltdown. The Bath Press, Bath, UK.

Waterston, D. 1913, (see Dawson, C. and Woodward A. S. Discussion session; $1913,69(273), 150)$, On the discovery of a Palaeolithic human skull and mandible in flint-bearing gravel overlying the Wealden (Hastings Beds) at Piltdown, Fletching, (Sussex). Abs Proc Geol Soc Lond (1912-13) pp 20-27 December 18 ${ }^{\text {th }}$, 1912, Dec.

Waterston, D. 1913. The Piltdown mandible. Nature 92, 319.

Weiner, J. S. 1955. The Piltdown Forgery. Oxford University Press, Oxford. See Fiftieth anniversary edition (2003) with new introduction and afterword by Chris Stringer ISBN 0-19-860780-6.

Weiner, J. S. 1973. Grafton Elliot Smith and Piltdown. In, ed. S. Zuckerman, The concepts of human evolution: Proceedings of a symposium held to commemorate the centenary of the birth of Grafton Elliot Smith. Symp Zool Soc London no. 33, pages 23-26.

Woodward, A. S. 1917. Fourth note on the Piltdown gravel with evidence of a second skull of Eoanthropus dawsoni. Quarterly Journal of the Geological Society London. 73, 1-10.

Woodward, S. A. 1921, A new cave man from Rhodesia, South Africa. Nature 108, 371-372.

Woodward, S. A. 1938. A fossil skull of an ancestral Bushman from the AngloEgyptian Sudan. Antiquity. A quarterly review of archaeology, 12, 190-193).

Woodward, S. A. 1948. The Earliest Englishman. Thinkers Library No. 127. Watts and Co. London. 
Zuckerman, S. 1973. Sir Grafton Elliot Smith 1871-1937. In, ed. S. Zuckerman, The concepts of human evolution: Proceedings of a symposium held to commemorate the centenary of the birth of Grafton Elliot Smith. Symp Zool Soc Lond no. 33, 3-21.

\section{Figure Legends}

Figure 1

The Piltdown 1 hominin assemblage $(F, G, H, I, J, K, L)$ alongside the bone implement (also known as "the cricket bat") (A), an eolith (B), palaeolith (D) and fragments of Mastodon (C) and horse (E) teeth.

Figure 2

Various reconstructions of the Piltdown skull. A, Smith Woodward and Pycraft's first attempt, B, Arthur Keith's first reconstruction, C, Smith Woodward's final reconstruction. An early reconstruction of the head of Piltdown Man by J. H. McGregor (D) contrasted here with a later reconstruction by Maurice Wilson created for the Exhibition of Britain in 1950 (E) and the portrait by Mr. John Cooke (F) that was eventually used as the frontispiece of The Earliest Englishman.

Figure 3

Scenes showing the excavations in progress at Piltdown around 1913. Dawson and Smith Woodward appear in them all along with Hargreaves, the workman, who appears in A, B and D. Teilhard de Chardin is pictured in photograph E together with Smith Woodward.

Figure 4

The Piltdown 2 vault bones $(A, C)$ and molar tooth (B) passed on to Smith Woodward after Dawson's death by his widow.

Figure 5

The Singa cranium (left) and Broken Hill cranium (right) were two human fossils studied and described by Arthur Smith Woodward.

Figure 6

Summary timeline of the key events in Arthur Smith Woodward's life and his involvement with human evolution. 
